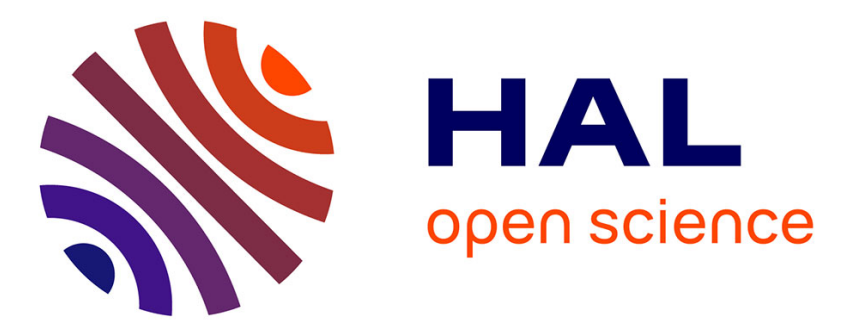

\title{
A first stage in the development of micromechanical simulations of the crystallographic propagation of fatigue cracks under multiaxial loading
}

Véronique Doquet

\section{- To cite this version:}

Véronique Doquet. A first stage in the development of micromechanical simulations of the crystallographic propagation of fatigue cracks under multiaxial loading. Fatigue and Fracture of Engineering Materials and Structures, 1998, 21 (6), pp.661-672. 10.1046/j.1460-2695.1998.00524.x hal-00111593

\author{
HAL Id: hal-00111593 \\ https://hal.science/hal-00111593
}

Submitted on 28 Feb 2019

HAL is a multi-disciplinary open access archive for the deposit and dissemination of scientific research documents, whether they are published or not. The documents may come from teaching and research institutions in France or abroad, or from public or private research centers.
L'archive ouverte pluridisciplinaire HAL, est destinée au dépôt et à la diffusion de documents scientifiques de niveau recherche, publiés ou non, émanant des établissements d'enseignement et de recherche français ou étrangers, des laboratoires publics ou privés.

\section{(ㄷ)(1) $\$$}

Distributed under a Creative Commons Attribution - NonCommerciall 4.0 International 


\title{
A FIRST STAGE IN THE DEVELOPMENT OF MICROMECHANICAL SIMULATIONS OF THE CRYSTALLOGRAPHIC PROPAGATION OF FATIGUE CRACKS UNDER MULTIAXIAL LOADING
}

\author{
V. Doquet \\ Laboratoire de Mécanique des Solides, URA-CNRS 317, Ecole Polytechnique, 91128 Palaiseau cedex, France
}

\begin{abstract}
Simulations of the nucleation of dislocations, glide and annihilation ahead of a fatigue crack growing along a localized slip band (a 'long' Stage I crack or a Stage II crack with a $K$ value close to the threshold) are performed for the case of push-pull or reversed torsion loadings, ignoring, in a first approach, the effect of grain boundaries. The crack growth rates are deduced from the dislocation flux at the crack tip. An influence of the normal stress on the friction between the crack flanks as well as on the condition for dislocation emission is introduced. A slower Stage I growth rate is then predicted for reversed torsion, consistent with experimental data.
\end{abstract}

Keywords_-Stage I crack; Fatigue; Mode II; Multiaxial; Simulations; Dislocations.

\section{INTRODUCTION}

It is widely acknowledged that reversed shear strain is the driving force for Stage I fatigue crack growth, but that the presence of an opening stress on highly sheared facets can assist the development of microcracks [1-3]. The absence of such an opening stress in the case of torsional loading is often considered responsible for slower Stage I growth and longer fatigue life compared with equivalent strain ranges in push-pull. As a consequence, most, if not all, multiaxial fatigue criteria $[4,5]$ incorporate both the maximum shear strain range and the stress (or strain) normal to the facets that undergo the maximum shear strain range. The relative magnitude of the second term has to be adjusted through materials constants so as to unify the tensile and torsional data. As was underlined in a previous paper [6], these material constants are extremely variable from one material to another, but we do not have any satisfactory explanation for this variability, because the effect the normal stress has during Stage I is not clear, from the point of view of the physical mechanism.

The aim of the present work is thus to suggest mechanisms by which the normal stress could influence Stage I fatigue crack development or the crystallographic propagation of a Stage II crack close to the threshold, and to represent them by micromechanical simulations of dislocation glide in the plastic zone, and then to try to derive some of the microstructural or mechanical parameters that could determine the influence of the normal stress.

The simulations are similar to those developed by Pippan [7], or Wilkinson and Roberts [8]. The difference is that the present study incorporates the effect of the normal stress on friction forces along crack flanks as well as on the condition for dislocation nucleation.

\section{PHILOSOPHY OF THE SIMULATIONS}

Stage I fatigue cracks grow along localized slip-bands. They are submitted to either pure shear loading (mixed mode II + III) in torsion, or combined opening and shear in push-pull. But plasticity, i.e. dislocation nucleation and glide, is only related to the shear components and is 
restricted to the slip band co-linear to the crack, otherwise there is a transition towards Stage II propagation (if non-coplanar slip is activated) [9]. As a consequence, and unlike the shear stresses, the singular opening stress is not relaxed (or shielded) by the dislocations stress field [10].

In the present simulations, only mixed mode I + II loading has been considered for the sake of simplicity. This means that the dislocations that are emitted and glide along the coplanar slip plane have a pure edge character (instead of mixed edge and screw when a mode III component is considered). They are supposed to be perfect dislocations. However, the possibility of cross-slip is not envisaged. This means that the present simulations are pertinent essentially for medium stacking-fault-energy F.C.C. metals and alloys.

Dislocations are supposed to be emitted from the crack tip as has often been observed during in situ tests performed in a transmission electron microscope [11].

No major microstructural obstacle to dislocation glide is considered as a first approach. This will be introduced in a forthcoming paper, since the interactions of the crack with the microstructure are an essential feature of Stage I growth. It is assumed that the tip of the plastic zone associated with the crack tip does not encounter any grain or twin boundary.

The geometry considered here (a straight, two-dimensional crack in an infinite half space) is thus very simple compared to the real geometry of Stage I cracks, but it is believed that such a simple model can, however, provide some insight into the crack growth mechanisms.

The author is aware of the limitations of Linear Elastic Fracture Mechanics in the case of short cracks. But, as in the work of Tanaka and Mura [3] who consider 'long stage I cracks', though still in the size range influenced by the microstructure, stress intensity factors will be used in the following. However, a 'correction for plasticity' will be introduced, as shown below, based on the stress field of dislocations [10]. This may be acceptable for torsional fatigue, where Stage I cracks can, in many instances, even in high-cycle fatigue, reach lengths that justify the use of LEFM before branching [12]. This can also be advocated for cyclically softening materials, e.g. Inconel 718, where Stage I cracks also reach a consequent size, even in push-pull [13], or for high strength steels with a fine microstructure (e.g. 4340 steel) where, according to Lankford [14] or Smith [15], the minimum crack length can be less than $100 \mu \mathrm{m}$, and yet careful use of LEFM parameters may yield reasonable predictions. In any case, this should not be a problem in describing crystallographic propagation of Stage II cracks when $\Delta K$ is close to the threshold, and as concerns Stage I cracks, this can be considered as an assumption whose relevance has to be evaluated with regard to the physical soundness of the resulting predictions.

Concerning the mode II stress intensity factor, allowance has to be made for the friction forces distributed along the crack flanks that make the effective stress intensity factor, $K_{\mathrm{II}}^{\text {eff }}$, different from its nominal value, $K_{\text {II }}^{\text {nom }}[16]$. These friction forces exist, even in pure mode II, because of the asperities of the crack flanks that are formed either when the crack adopts a zig-zag path between several parallel slip bands in the same grain, or when it crosses a grain boundary and is thus slightly tilted because of a difference in crystallographic orientation. The reality of these friction forces is demonstrated in Fig. 1 by the wear debris coming out of the mouth of a Stage I crack photographed during a combined tension and torsion test carried out in a SEM on a tubular specimen of Co45Ni. Lynch and Ryder [17] have shown how much Stage I growth rate in an aluminium alloy submitted to torsional fatigue is affected by a modification of the tribological conditions: in the presence of an inert fluid that tends to remove the fretting debris from the crack flanks, a four-fold increase in Stage I crack growth rate is observed, whereas Stage II crack growth rate is decreased.

Friction forces will of course be intensified in the presence of a normal compressive stress and reduced if there is an opening stress. 

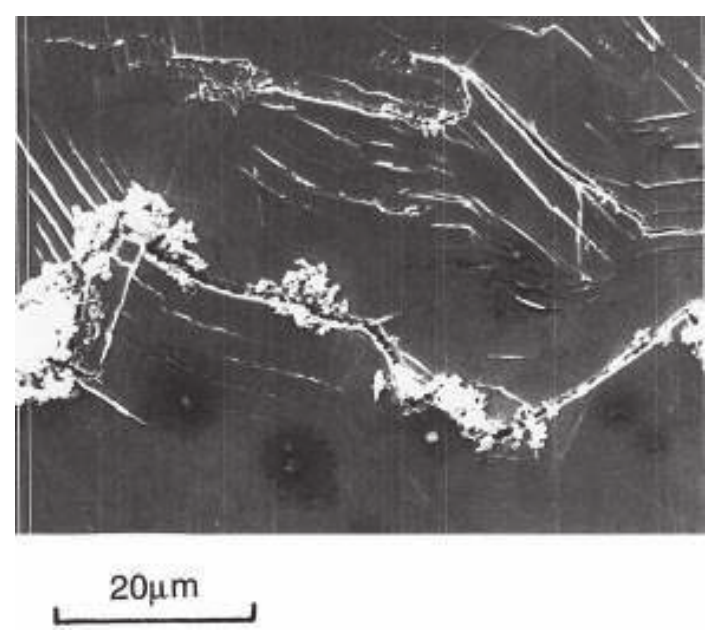

Fig. 1. Aspect of a Stage I crack formed in a Co45Ni alloy under $90^{\circ}$ out-of-phase tension and torsion loading.

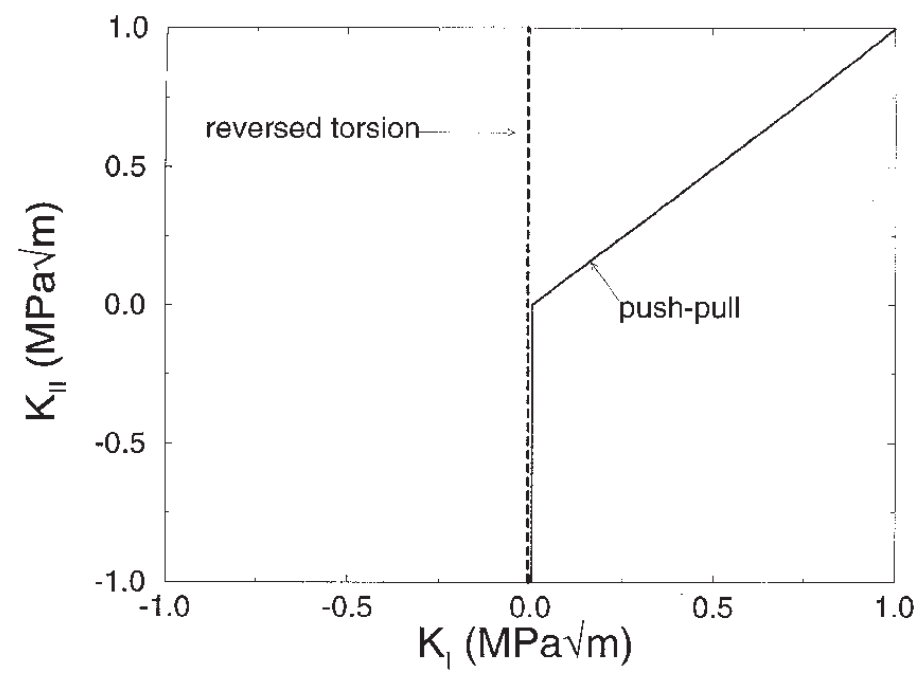

Fig. 2. Nominal loading paths, in terms of stress intensity factors, for a crack lying along a maximum shear strain plane under reversed torsion and push-pull.

Let us now consider that $n$ edge dislocations with Burgers vector $b_{i}= \pm b$ (depending on their sign) are present in the plastic zone. Considering the shear stress produced by each dislocation along the plane of the crack, it can be shown [10] that they have a shielding effect on the stress distribution at the crack tip, characterized by

$$
K_{\mathrm{II}}^{\mathrm{tip}}=K_{\mathrm{II}}^{\mathrm{eff}}-\sum_{i=1}^{n} \frac{\mu b_{i}}{(1-v) \sqrt{2 \pi x_{i}}}
$$

where $x_{i}$ stands for the distance of the $i$-th dislocation from the crack tip. $\mu$ and $v$ are the shear elastic modulus and Poisson's ratio, respectively.

The criterion for dislocation nucleation at a crack tip was recently analysed by Rice [18] on the basis of the Peierls concept. A tension-shear coupling equation, based on atomic models, was later established by Sun et al. [19]. According to them, nucleation occurs if $K_{\mathrm{II}}^{\text {tip }}$ reaches a critical value, $K_{\mathrm{II}}^{\text {nucl }}$, with:

$$
K_{\text {II }}^{\text {nucl }}=\sqrt{\frac{2 \mu}{(1-v)}\left[\gamma_{\text {us }}^{\mathrm{r}}-\alpha\left(\gamma_{\text {us }}^{\mathrm{u}}-\gamma_{\text {us }}^{\mathrm{r}}\right)\left(\frac{\pi}{2}-\psi\right)\right]}
$$

where $\psi=\arctan \left(K_{\mathrm{II}} / K_{\mathrm{I}}\right)$ is the phase angle between mode I and II loadings. (In torsion, a pure shear case, $\psi=\Pi / 2$, whereas for push-pull, at any time, the normal and shear stresses are equal in magnitude, but since $K_{\mathrm{I}}$ is zero when the normal stress is compressive, $\psi=\Pi / 4$ during the tensile phase and $\Pi / 2$ in the compressive phase, see Fig. 2). $\alpha$ is a positive constant that depends on the crystallographic and electronic structure of the material. $\gamma_{u s}$ is termed 'the unstable stacking energy'. It is defined as the energy increase per unit area of slip plane when the lattice on one side of the plane is shifted relative to the lattice on the other side, to the unstable equilibrium position at or near to a sliding displacement of $b / 2$. Now, this can be achieved in two ways, either letting a certain amount of opening displacement occur (this is the relaxed case) or without any opening displacement (this is the unrelaxed case). The latter case corresponds to a value $\gamma_{\text {us }}^{\mathrm{u}}$ of $\gamma_{\text {us }}$, which is higher than $\gamma_{\mathrm{us}}^{\mathrm{r}}$ in the previous case. Equation (2) thus predicts a lower threshold stress intensity factor for dislocation nucleation when $\psi$ decreases, i.e. when an opening stress is present. 
In this paper, only fully reversed loadings are envisaged (the effect of the $K_{\min } / K_{\max }$ ratio will be treated in a forthcoming paper), so that $K_{\mathrm{II}}$ changes sign. As a consequence, negative as well as positive edge dislocations can be emitted when, respectively:

$$
K_{\mathrm{II}}^{\mathrm{tip}} \leqslant-K_{\mathrm{II}}^{\text {nucl }} \quad \text { or } \quad K_{\mathrm{II}}^{\mathrm{tip}} \geqslant K_{\mathrm{II}}^{\text {nucl }}
$$

Once emitted, these dislocations glide or rest according to the law:

$$
v_{i}=v_{0} \operatorname{sign}\left(b_{i}\right) \cdot \operatorname{sign}\left(\tau_{i}\right) \cdot\left\langle\left|\tau_{i}\right|-\tau_{\mathrm{f}}\right\rangle^{\mathrm{m}} \quad \text { where }\langle x\rangle \text { is zero if } x \leqslant 0 \text { and } x \text { otherwise }
$$

where $v_{i}$ is the velocity of the $i$-th dislocation, $\tau_{\mathrm{f}}$ is the lattice friction on the dislocations, $v_{0}$ and $m$, two constants. $\tau_{i}$ is the shear stress on the $i$-th dislocation, i.e. according to Ohr [11]:

$$
\tau_{i}=\frac{K_{\text {II }}^{\text {eff }}}{\sqrt{2 \Pi x_{i}}}-\frac{\mu b_{i}}{4 \Pi(1-v) x_{i}}-\sum_{j \neq i} \frac{\mu b_{j}}{2 \Pi(1-v)} \sqrt{\frac{x_{j}}{x_{i}}} \cdot \frac{1}{x_{j}-x_{i}}
$$

The second term on the right-hand-side of Eq. (5) represents the image stress on the dislocation due to the free surface of the crack, the third term is the shear stress due to the other dislocations (and their own image dislocations, hence the $\sqrt{x_{j} / x_{i}}$ term).

Annihilation between a positive and negative dislocation is allowed when their mutual distance is less than a critical value $y_{\mathrm{e}}$. A dislocation will return to the crack tip and then annihilate if it approaches closer than a critical distance $y_{\mathrm{r}}$.

The cyclic loading path is followed by incremental time steps, $\Delta t$, small enough for the velocity of each dislocation to be considered constant over $\Delta t$. In practice, $\Delta t$ is continuously adjusted so that, during one time step, dislocations move at most by a set fraction of the distance to their nearest neighbour's previous position.

Two successive cycles only are simulated because the second cycle is representative of the steady state.

The crack is considered to grow by one Burgers vector each time a pair of positive-negative dislocations has been emitted at the crack tip, or when a positive (or negative) dislocation returns to the crack tip. In the latter case, it is assumed that even though the crack tip geometry before the dislocation nucleation is, in principle, recovered when this dislocation comes back, the free surface increment created at nucleation, that has been exposed to the environment and hence gas adsorption, cannot be rewelded. Both events (positive-negative pair emission, or emission and return of a dislocation) correspond to some cyclic plastic flow at the crack tip and should thus contribute to its growth.

\section{IMPLEMENTATION OF THE SIMULATIONS}

The nominal stress intensity factors at the crack tip are calculated at each time-step as:

$$
\begin{gathered}
K_{\mathrm{I}}=\sigma_{\mathrm{ncp}} \cdot \sqrt{\pi a} \text { when } \sigma_{\mathrm{ncp}} \geqslant 0 \\
K_{\mathrm{II}}^{\text {nom }}=\tau_{\mathrm{cp}} \cdot \sqrt{\pi a}
\end{gathered}
$$

where $\sigma_{\mathrm{ncp}}$ and $\tau_{\mathrm{cp}}$ are the current values of the normal stress and shear stress on the critical plane (i.e. the plane where the shear stress range is maximum), respectively.

Experimental information concerning crack flanks frictional interactions for a long crack loaded in mode II has been obtained, for a maraging steel, in the framework of other studies $[12,16]$. Precracked specimens, covered with square-shaped microgrids with a $5 \mu \mathrm{m}$ pitch were loaded in shear inside the chamber of the scanning electron microscope, and the displacement profiles 
measured using microgrids as reference marks. It was shown that the measured displacements resulted from the superposition of the nominal load and a uniform friction stress, ranging from 20 to $70 \mathrm{MPa}$ (depending on crack flanks roughness) in the absence of a normal stress, and reaching $110 \mathrm{MPa}$ when a $150 \mathrm{MPa}$ compressive stress was applied. In addition, a thin tubular specimen containing a transversal crack has been progressively loaded in torsion, after the application of a tensile or compressive stress, inside the SEM, and the threshold stress intensity factor for which slip was observable at the crack tip was measured. The results are plotted in Fig. 3 as a function of the normal stress, $\sigma_{\mathrm{n}}$. It can be seen that the influence of a compressive normal stress on crack flanks friction is more significant than that of an opening stress: a $80 \mathrm{MPa}$ opening stress seems sufficient to reduce the frictional resistance to crack flanks sliding to zero, but $\approx 230 \mathrm{MPa}$ is necessary, in compression, to double this resistance.

In the present study, an attempt is made to reproduce these effects qualitatively through empirical equations.

The influence of the normal stress, $\sigma_{\mathrm{n}}$, on the friction shear stress, $c$, distributed along the whole crack length, $2 a$, is expressed by:

$$
\begin{array}{ll}
c=c_{0} \exp \left(-k_{+} \cdot \sigma_{n}\right) & \text { if } \sigma_{n} \geqslant 0 \\
c=c_{0} \exp \left(-k_{-} \cdot \sigma_{n}\right) & \text { if } \sigma_{n} \leqslant 0
\end{array}
$$

$c_{0}$ is a constant which characterizes the friction stress in the absence of any normal stress, and is thus related to the tortuosity of the crack path, which is generally less pronounced for a Stage I crack than for the long cracks involved in the study mentioned above. The order of magnitude of $c_{0}$ will thus be $5-10 \mathrm{MPa}$ in the simulations. $k_{+}$and $k_{-}$are two constants, the latter connected with the friction coefficient of the material. Most of the simulations will be performed with $k_{+}=$ $0.057, k_{-}=0.014$. (This means that $c$ is divided by 100 for $\sigma_{\mathrm{n}}=80 \mathrm{MPa}$, but it is only multiplied by three for $\sigma_{\mathrm{n}}=80 \mathrm{MPa}$.) The value chosen for $k_{-}$leads to a stronger influence of $\sigma_{n}$ on frictional effects than that measured in maraging steel, since in many FCC materials, crack flanks asperities must impinge more easily, crashed against one another by a compressive force, than in this high strength steel, thus leading to enhanced frictional effects.

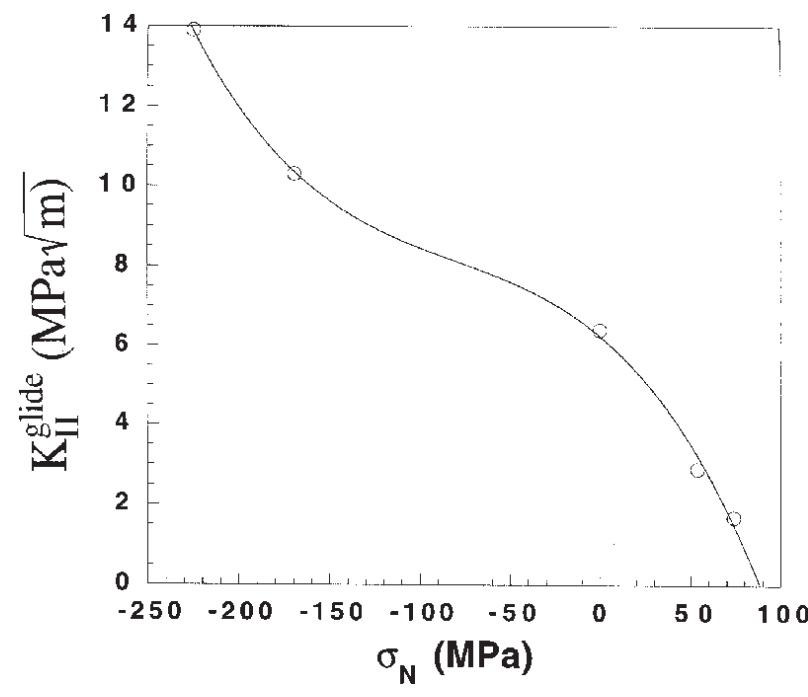

Fig. 3. Variation of the mode II stress intensity factor at the onset of glide, measured at the tip of a crack progressively loaded in plane shear, in a maraging steel.

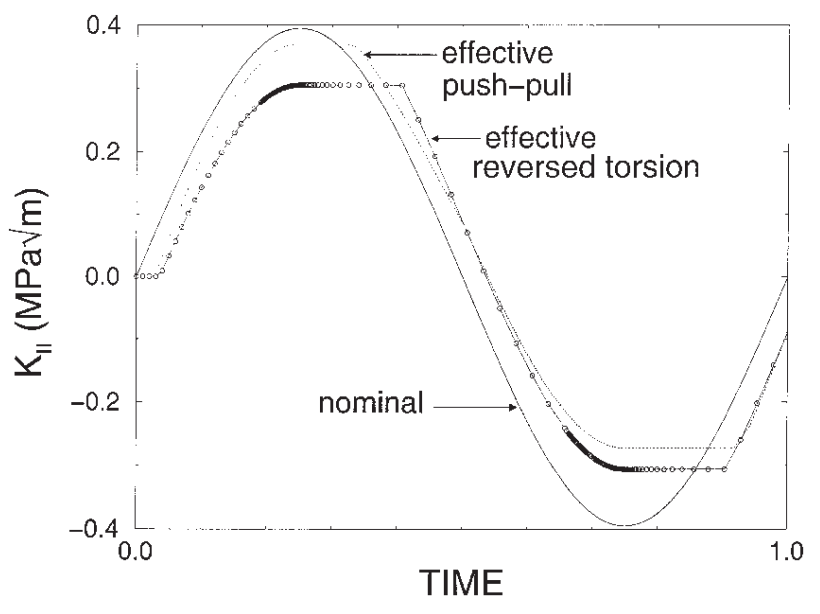

Fig. 4. Variation of nominal and effective mode II stress intensity factors for a crack lying along the maximum shear stress plane under (Tresca) reversed torsion and push-pull loadings of equivalent amplitude. $c_{0}=5 \mathrm{MPa}, k_{+}=0.057$, $k_{-}=0.014$. 
It follows:

$$
K_{\mathrm{II}}^{\mathrm{eff}}=K_{\mathrm{II}}^{\mathrm{nom}} \pm c \sqrt{\Pi a}
$$

the sign affecting the second term depending on the loading $(-)$ or unloading $(+)$ situation. Of course, when the loading changes direction, there will be periods where $K_{\text {II }}^{\text {nom }}$ changes, but $K_{\text {II }}^{\text {eff }}$ remains constant, until the frictional resistance to reverse crack flanks slip is overcome.

Figure 4 shows how $K_{\text {II }}^{\text {nom }}$ and $K_{\text {II }}^{\text {eff }}$ vary in time during a reversed torsion and push-pull cycle described, respectively, by: $\tau=\tau_{0} \cdot \sin \omega t, \sigma=\sigma_{0} \cdot \sin \omega t$, with $\sigma_{0}=2 \tau_{0}$ (equivalent stress ranges in the sense of Tresca), assuming that the crack lies along the maximum shear strain plane in each case (i.e. longitudinal/transversal or at $45^{\circ}$ to the tensile axis, respectively). Note that $\Delta K_{I I}^{\text {nom }}$ is the same in both cases.

Sun et al. [19] have calculated numerical values of $\gamma_{\mathrm{us}}^{\mathrm{u}}, \gamma_{\mathrm{us}}^{\mathrm{r}}$ and $\alpha$ for various metals. For Al and $\mathrm{Ni} \gamma_{\text {us }}^{\mathrm{r}} / \gamma_{\mathrm{us}}^{\mathrm{u}}$ is $\approx 0.866$ and $\alpha=1.2$, so that Eq. (2) gives a nucleation stress intensity factor in the tensile phase of the push-pull cycle that is $92 \%$ of its value in torsion or in the compressive part of the cycle. (Note that the effect would be more pronounced for $90^{\circ}$ out-of-phase tension and torsion loading - a case for which $\psi$ varies continuously between 0 and $\Pi / 2$, and consequently, $K_{\text {II }}^{\text {nucl }}$ can be as low as $84 \%$ of its value in pure shear. This case thus deserves a special study.)

$K_{\mathrm{II}}^{\text {nucl }}$ for pure mode II was set to $0.3 \mathrm{MPa} \sqrt{\mathrm{m}}$ in accordance with the order of magnitude given in Ref. [11].

The critical distance for positive-negative dislocations annihilation, $y_{\mathrm{e}}$, was taken as $16 \mathrm{~nm}$, which is the annihilation distance for edge dipoles in copper given by Essmann and Differt [20].

The critical distance for dislocation annihilation at the crack tip, $y_{\mathrm{r}}$, was chosen as $10^{-10} \mathrm{~m}$, which is the order of magnitude of the core radius.

A lattice friction force $\tau_{\mathrm{f}}$ of $20 \mathrm{MPa}$ was chosen, which is close to the local shear stress measured in the channels of persistent slip bands in copper by Lepinoux and Kubin [21].

The constants in the expression of dislocations velocity [Eq. (4)] are chosen as $v_{0}=13 \mathrm{~ms}^{-1}$ and $m=0.88$, which are typical experimental values for FCC metals [8].

\section{RESULTS}

\section{Pure shear case (reversed torsion)}

The sequence of events and the positions of the dislocations during two loading cycles in reversed torsion with $K_{\mathrm{II}, \max }^{\text {nom }}=0.394 \mathrm{MPa} \sqrt{\mathrm{m}}$ and a friction stress $c_{0}=5 \mathrm{MPa}$ along the crack flanks are sketched in Figs 5 and 6.

Nothing happens initially while $K_{\text {II }}^{\text {tip }}$ is less than $0.3 \mathrm{MPa} \sqrt{\mathrm{m}}$. Then, five positive dislocations are successively nucleated, producing, each time, a shielding effect that decreases quickly as the dislocation glides away from the crack tip [see the serrated evolution of $K_{\mathrm{II}}^{\text {tip }}$ in Fig. 5(b)].

Note [Fig. 6(b)] the existence of a dislocation-free zone (D.F.Z.) between the crack-tip and the last emitted dislocation. This fact, consistent with experimental observations [11], does not follow naturally from approaches based on continuously distributed dislocations that ignore image forces, as in the work of Bilby, Cottrell and Swinden [22], but they can be introduced, as in the work of Weertman et al. [23], who consider dislocations distributed along two slip planes parallel to the crack, one above and one below the crack plane, and 'assume a dislocation-free zone in front of the crack to correspond to the slip plane separation'.

Nothing occurs then during a large portion of the unloading phase because of the stationary value of $K_{\mathrm{II}}^{\text {eff }}$ on one hand [see Fig. 5(a)] and the lattice friction that delays the reversed motion of the dislocations on the other hand. 

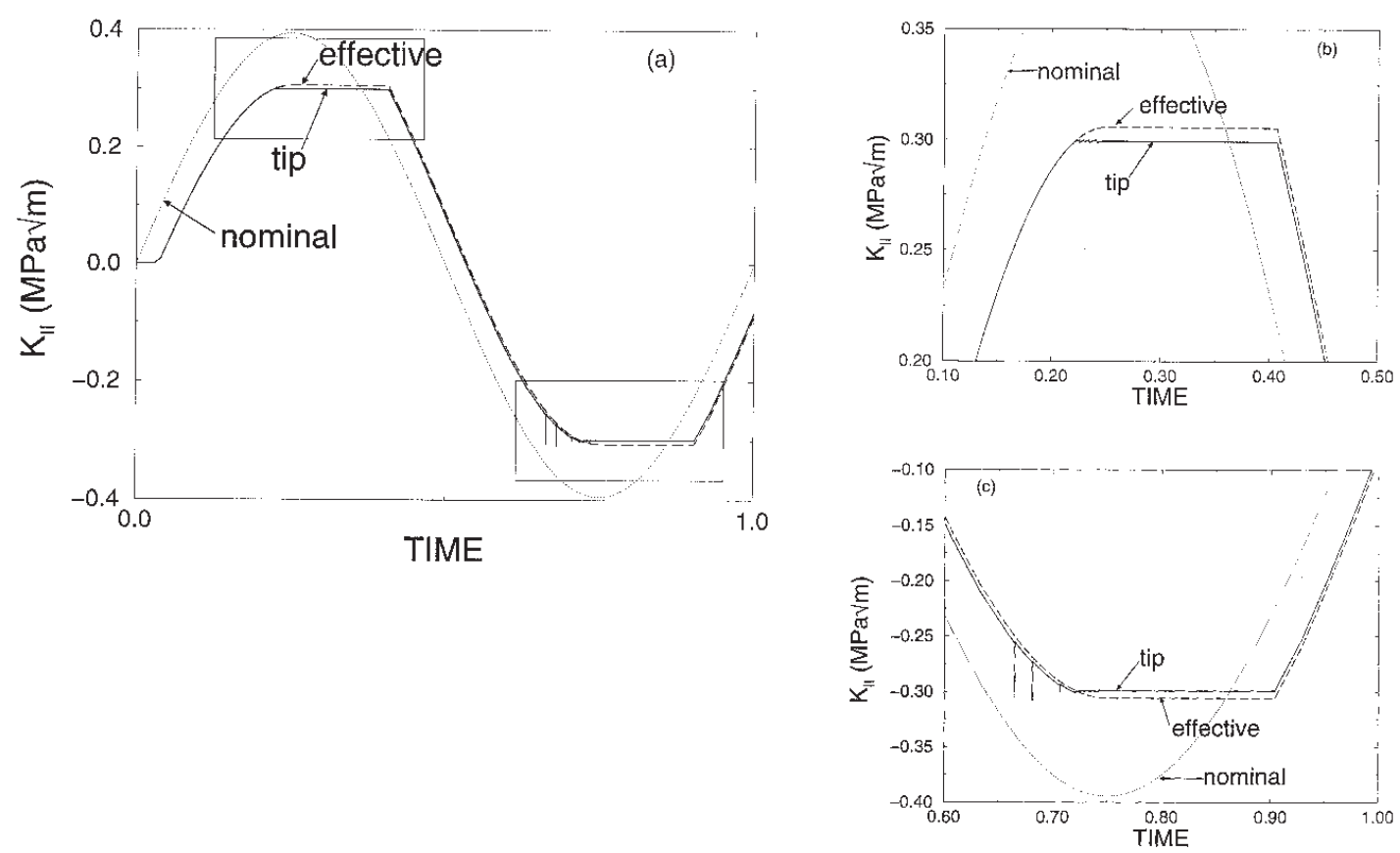

Fig. 5. Results of $K_{\mathrm{II}}$ values from the simulation in the pure shear case (reversed torsion). $c_{0}=5 \mathrm{MPa}$, $\tau_{\mathrm{f}}=20 \mathrm{MPa}, K_{\mathrm{II}}^{\text {nucl }}=0.3 \mathrm{MPa} \sqrt{\mathrm{m}}$. (a) Variation of $K_{\mathrm{II}}^{\text {nom }}, K_{\mathrm{II}}^{\text {eff }}$ and $K_{\mathrm{II}}^{\text {tip }}$ with time. (b), (c): details of (a).
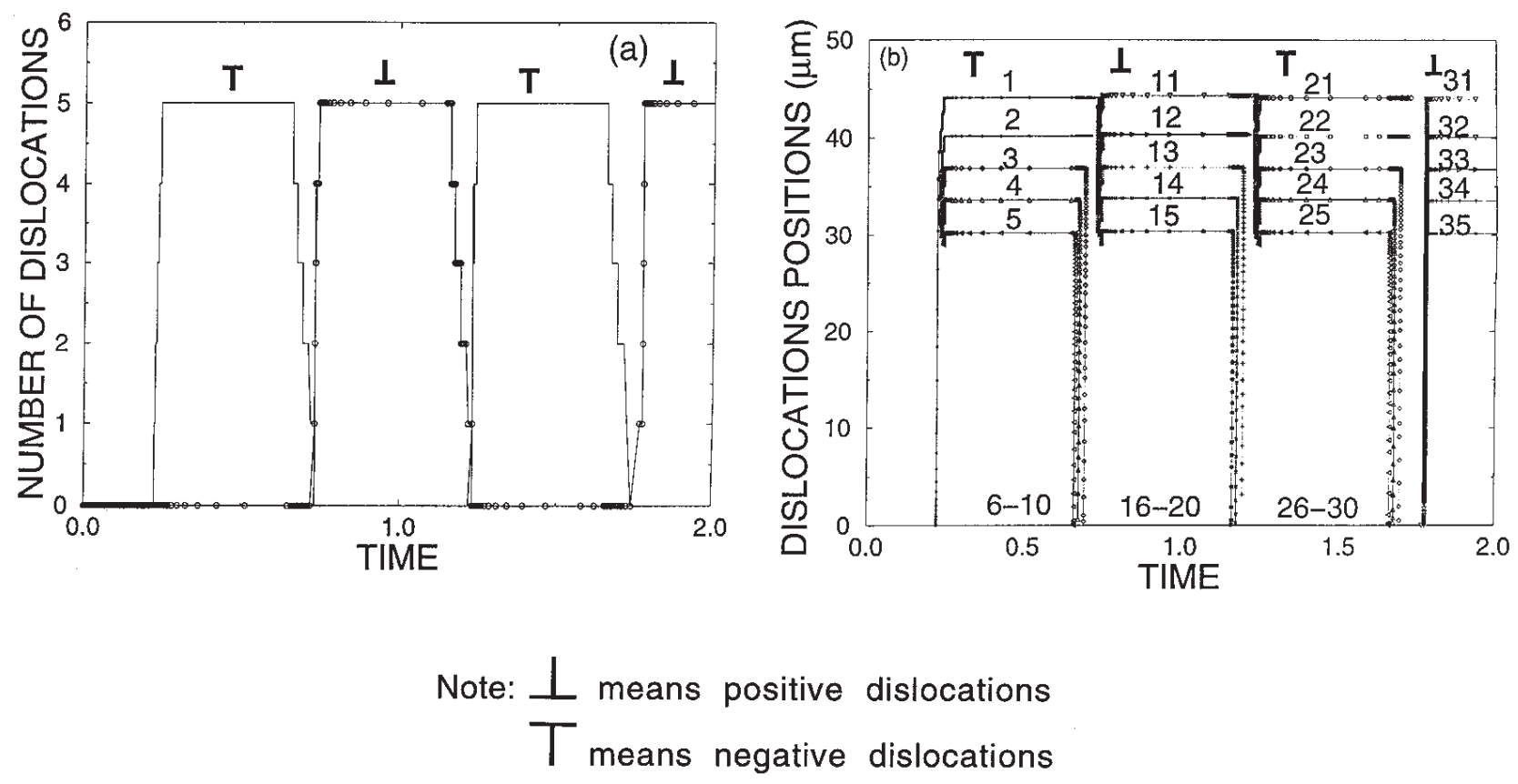

Fig. 6. Results of the simulation in the pure shear case (reversed torsion) $c_{0}=5 \mathrm{MPa}, \tau_{\mathrm{f}}=20 \mathrm{MPa}$, $K_{\mathrm{II}}^{\text {nucl }}=0.3 \mathrm{MPa} \sqrt{\mathrm{m}}$. (a) Number of dislocations in the plastic zone. (b) Positions of the dislocations. (The dislocations are numbered in the chronological order of their emission. Those which annihilate others soon after their emission are mentioned only by number.)

The last emitted dislocation is the first to be unlocked and, as $K_{\mathrm{II}}^{\text {eff }}$ grows negative, it travels back to the crack tip, where its sudden antishielding effect [evidenced by a serration on the $K_{\text {II }}^{\text {tip }}$ curve of Fig. 5(c)] leads to the emission of a negative dislocation. Annihilation of the positive and 
negative dislocations follows, and $K_{\text {II }}^{\text {tip }}$ recovers its 'regular' value until the following positive dislocation stacked in the plastic zone travels back to the crack tip in its turn.

This process is repeated until the third emitted positive dislocation has been annihilated. The last two positive dislocations remaining in the plastic zone, however, do not travel back to the crack tip for two reasons: first, the back-stress due to preceding dislocations, that would favour a reverse motion, is weak for the second one and null for the first one; and second, the decrease of $K_{\text {II }}^{\text {eff }}$ is slower and slower (sinusoidal nominal waveform), and perhaps not sufficient to overcome the lattice frictional resistance to dislocation glide.

The next negative dislocation nucleated comes to meet the second positive one and annihilate it.

Then, two additional negative dislocations are nucleated before the first one approaches the last remaining positive one close enough to annihilate it. Two additional negative dislocations are nucleated before 'unloading', during which four of the five negative dislocations present in the plastic zone return to the crack tip where they promote the emission of positive nucleations and annihilate them, whereas the last one will be annihilated later by a positive dislocation coming to meet it.

After that, a similar sequence of events repeats itself and finally, the computed crack growth during the second period is 10 Burgers vectors.

Similar simulations have been carried out for various loading ranges and various friction stresses $c_{0}$. The results are drawn in a bilogarithmic $\mathrm{d} a / \mathrm{d} N$ versus $\Delta K_{\mathrm{II}}^{\text {nom }}$ plot in Fig. 7.

It can be seen that the existence of a threshold stress intensity range below which the crack does not propagate for lack of cyclic plasticity at the tip, as well as the well-known shape of $\mathrm{d} a / \mathrm{d} N$ versus $\Delta K$ curves in the vicinity of this threshold are qualitatively reproduced by the simulations, as in the work of Wilkinson and Roberts [8], and Pippan [7].

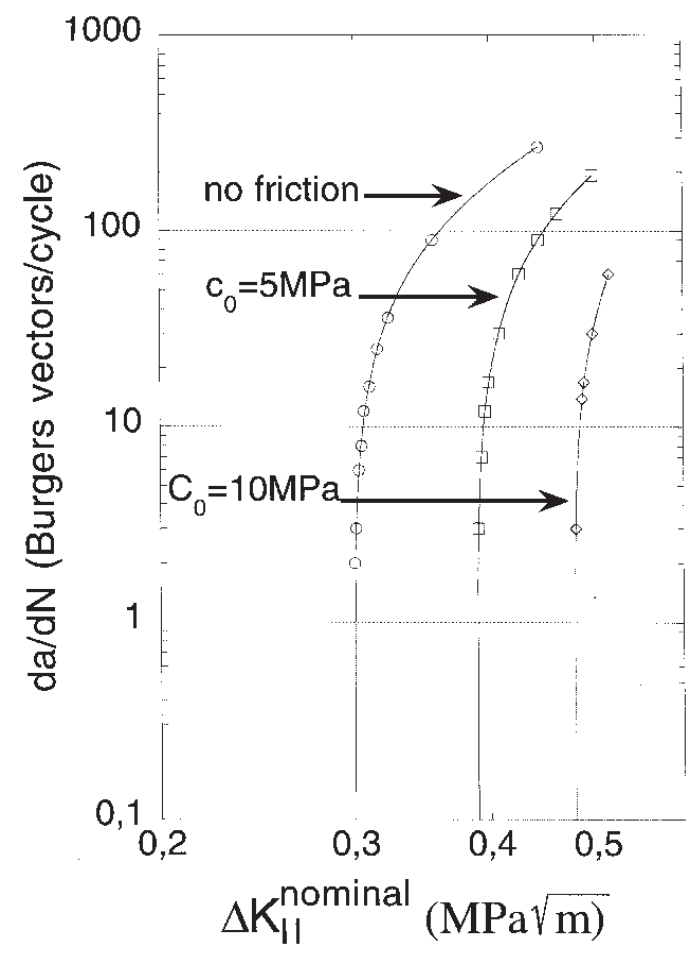

Fig. 7. Crack growth rates calculated for various friction stresses versus nominal $\Delta K_{\text {II }}$ in the pure shear case (reversed torsion). 
In addition, the influence of the friction stress along the crack flanks is illustrated: quite similarly to the closure effects for mode I propagation, the friction effects shift the $\mathrm{d} a / \mathrm{d} N$ versus $\Delta K_{\text {II }}^{\text {nom }}$ curve compared to the 'intrinsic' curve corresponding to zero friction. In the absence of quantitative data on the friction stresses along the flanks of a Stage I crack, a discussion on the calculated values of the threshold stress intensity factors would be premature, and what is more, experimental values of mode II thresholds in single crystals, that could be compared to the calculated values, seem to be rare. This threshold for cyclic plasticity at the crack tip is clearly less relevant for engineering applications than the threshold for grain boundaries crossing which is, in many instances, intimately connected with the fatigue limit.

In phase opening and shear case (push-pull)

Figure 8 shows the results of a simulation performed for $K_{\text {II, } \operatorname{nax}}^{\text {nom }}=0.394 \mathrm{MPa} \sqrt{\mathrm{m}}$ and $c_{0}=$ $5 \mathrm{MPa}$ (as in the previous case of Figs 5 and 6, i.e. reversed torsion) in the case of push-pull loading.

It can be seen that the positive dislocations nucleated in the tensile phase are much more numerous than in the pure shear case ( 77 instead of five), because of a higher maximum effective stress $(0.369 \mathrm{MPa} \sqrt{\mathrm{m}}$ instead of $0.306 \mathrm{MPa} \sqrt{\mathrm{m}})$ and a lower nucleation threshold.

The truncation of the $K_{\mathrm{II}}^{\text {eff }}$ cycle in the compressive part of the cycle $\left(K_{\mathrm{II}, \mathrm{efin}}^{\mathrm{eff}}=0.273 \mathrm{MPa} \sqrt{\mathrm{m}}\right.$ only, because of enhanced frictional effects) does not, however, allow all these dislocations to return to the crack tip, and 28 of them stay in the plastic zone. [There again, those which return to the crack tip are responsible for a sudden shielding that disappears when the dislocation annihilates, hence the serrated evolution of $K_{\text {II }}^{\text {tip }}$ in Fig. 8(a).]

The crack growth rate per cycle (49 Burgers vectors) is nevertheless much higher than in the pure shear case.

Several such simulations were performed for push-pull with various loading ranges and friction stresses, $c_{0}$. The results are compared to torsional results in Fig. 9 in the form of $\mathrm{d} a / \mathrm{d} N$ versus $\Delta K_{\text {II }}^{\text {nom }}$ curves.

Comparing the curves labelled A and B, it appears that even without friction, the crack growth rates are higher in push-pull than in reversed torsion, but the difference, appreciable for small loading ranges, vanishes as the loading range increases. This is probably because close to the threshold, the critical stage for crack propagation is dislocation nucleation, which is made easier
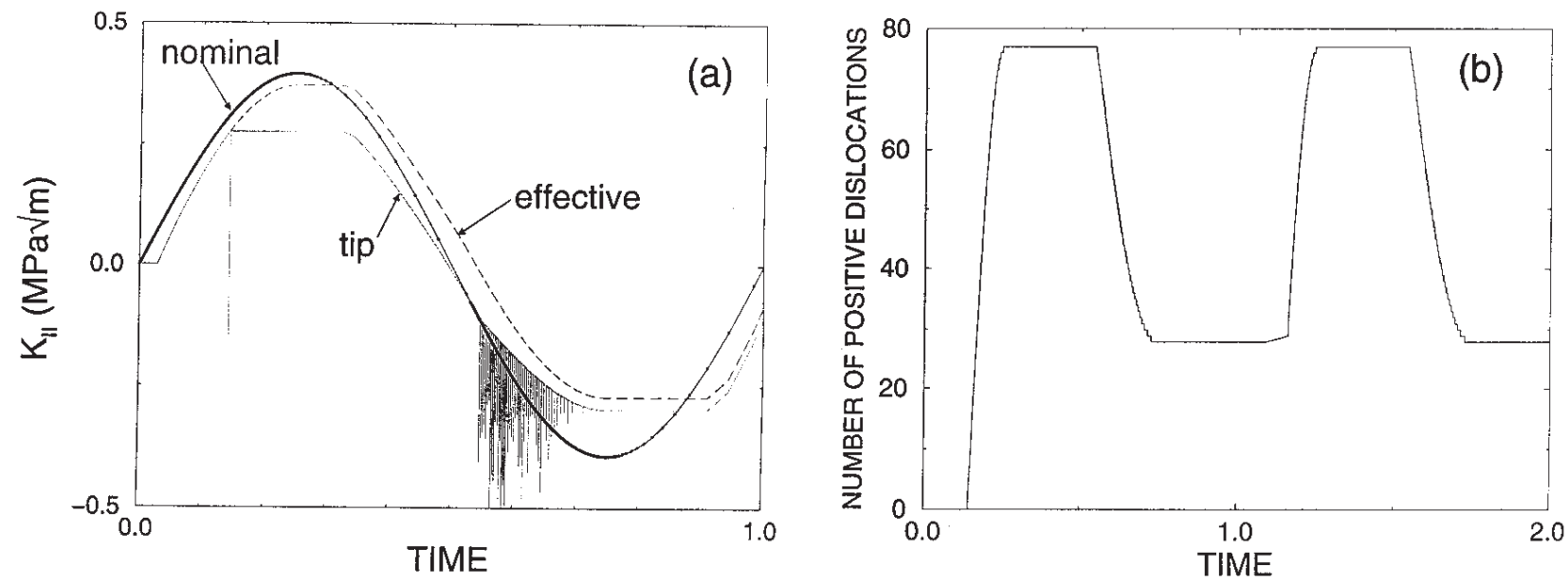

Fig. 8. Results of the simulation in the case of in-phase mixed opening and shear (push-pull). $c_{0}=5 \mathrm{MPa}, \tau_{\mathrm{f}}=20 \mathrm{MPa}, K_{\text {II }}^{\text {nucl }}=0.3 \mathrm{MPa} \sqrt{\mathrm{m}} . k_{+}=0.057, k_{-}=0.014$. (a) Variation of $K_{\mathrm{II}}^{\text {nom }}, K_{\mathrm{II}}^{\text {eff }}$ and $K_{\text {II }}^{\text {tip }}$ with time. (b) Number of dislocations in the plastic zone. 


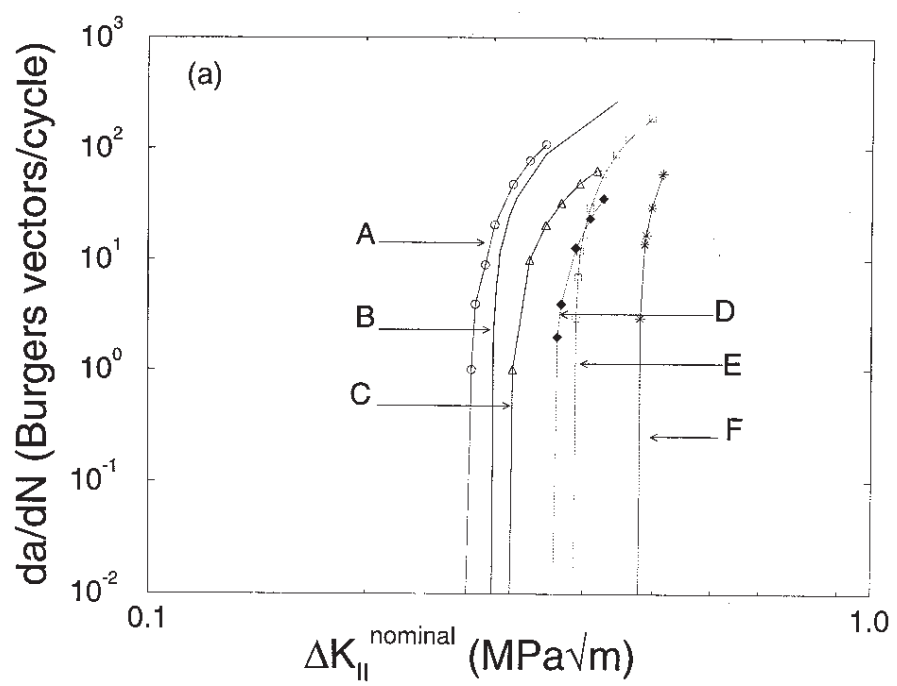

Fig. 9. Comparison of the calculated crack growth rates versus nominal $\Delta K_{\text {II }}$ curves. (A) push-pull, no friction; (B) reversed torsion, no friction; (C) push-pull, $c_{0}=5 \mathrm{MPa}$; (D) push-pull, $c_{0}=10 \mathrm{MPa}$;

(E) reversed torsion, $c_{0}=5 \mathrm{MPa}$; $(\mathrm{F})$ reversed torsion, $c_{0}=10 \mathrm{MPa}$.

by the opening stress, in push-pull, whereas for higher loads, nucleation is no longer critical, but reverse dislocation glide, which is more natural under reversed torsion, is. According to this trend, the ratio between torsional and tensile fatigue lives should thus increase as the loading range decreases. This corresponds to experimental observations and is thus very encouraging [6].

At this stage of the study, the mere effect of the normal stress on the nucleation threshold does not seem to be a sufficient explanation for the differences in fatigue lives usually observed between push-pull and reversed torsion. But this conclusion might change with the introduction of grain boundaries against which the dislocations emitted by the crack will pile up, thus generating stress concentrations in the neighbouring grain. The higher number of dislocations emitted in push-pull for an equivalent loading range should generate higher stress concentrations, thus promoting slip activation in the next grain and thus, probably, an easier crossing of the grain boundary.

Besides, when the influence of the normal stress on crack flanks friction is introduced, the difference in Stage I kinetics between the two loading modes is increased, and this difference is amplified when the friction stress $c_{0}$ increases (compare curves $\mathrm{C}$ and $\mathrm{E}$, or D and $\mathrm{F}$ in Fig. 9).

\section{CONCLUSIONS}

As a preliminary stage towards a simulation of the crystallographic propagation of fatigue cracks, the crack development process by the emission/annihilation of dislocations at the crack tip has been simulated, ignoring, in a first approach, the effect of grain boundaries. The originality of these simulations lies in two aspects. First, in the distinction made between nominal and effective loading, allowance is made for the friction stresses that resist the sliding of crack flanks, these stresses being either decreased or enhanced by a normal stress; and second, in the incorporation of tension-shear coupling with respect to the critical stress intensity for dislocation nucleation, following Rice and co-workers.

The crack speed $(\mathrm{d} a / \mathrm{d} N)$ versus $\Delta K$ curves were obtained for push-pull and reversed torsion. The existence of a threshold stress intensity factor for crack growth, as well as the shape of the $\mathrm{d} a / \mathrm{d} N$ versus $\Delta K$ curves in the vicinity of the threshold are qualitatively reproduced. The influence 
of friction stresses along the crack flanks is also clearly illustrated: it shifts the $\mathrm{d} a / \mathrm{d} N$ versus $\Delta K_{\mathrm{II}}^{\text {nom }}$ curve to higher $\Delta K$ values compared to the 'intrinsic' curve corresponding to zero friction.

Due to the effect of a normal stress on the dislocation nucleation threshold, crystallographic growth is predicted to be slower under reversed torsion than under push-pull for equivalent (Tresca) stress (or strain) ranges, and the ratio between torsional and tensile fatigue lives is predicted to increase as the loading range decreases, which is consistent with experimental data on many materials. The difference in the crack growth rates calculated under the two loading modes is amplified when normal stress-dependent frictional effects are introduced.

If the mechanisms proposed here to explain the influence of the normal stress on Stage I fatigue crack growth were pertinent, the difference between tensile and torsional fatigue lives should thus depend on the roughness of Stage I cracks and the friction coefficient of the material, both affecting the intensity of the friction stress along the crack flanks. It should also depend on the crystallographic and electronic structure of the material, which determine the degree of tension-shear coupling in relation to dislocations emission. Very specific experiments have to be designed to check these points.

Some results of the simulations suggest that the interaction between a Stage I crack and a grain boundary should be different under push-pull and reversed torsion. Work is thus now in progress to complete the model by taking into account the existence of microstructural obstacles to dislocation glide (essentially, grain and twin boundaries). The possibility of a non-zero mean stress should also be introduced. Stage I crack growth under multiaxial non-proportional loadings deserves special investigation.

\section{REFERENCES}

1. Z. X. Tong, L. Liu, S. Lin and C. M. Hsiao (1986) Kinetic study on the propagation of fatigue crack in pure aluminium single crystals under different modes of loading. Scripta Metall. 20, 967-970.

2. M. Gell and G. R. Leverant (1968) The characteristics of Stage I fatigue fracture in a high strength nickel alloy. Acta Metall. 16, 553-561.

3. K. Tanaka and T. Mura (1984) Fatigue crack growth along planar slip bands. Acta Metall. 32(10), $1731-1740$.

4. M. W. Brown and K. J. Miller (1973) A theory for fatigue failure under multiaxial stress-strain conditions. Proc. Inst. Mech. Engrs 187, 65-73.

5. A. Fatemi and D. F. Socie (1988) A critical plane approach to multiaxial fatigue damage including outof-phase loading. Fatigue Fract. Engng Mater. Struct. 11, 149-165.

6. V. Doquet (1997) Crack initiation mechanisms in torsional fatigue. Fatigue Fract. Engng Mater. Struct. 20, 227-235.

7. R. Pippan (1991) Dislocation emission and fatigue crack growth threshold. Acta Metall. Mater. 39(3), 255-262.

8. A. J. Wilkinson and S. G. Roberts (1996) A dislocation model for the two critical stress intensities required for threshold fatigue crack propagation. Scripta Mater. 35(11), 1365-1371.

9. D. A. Koss and K. S. Chan (1980) Fracture along planar slip bands. Acta Metall. 28, 1245-1252.

10. I. H. Lin and R. Thomson (1986) Cleavage, dislocation emission, and shielding for cracks under general loading. Acta Metall. 34, 187-206.

11. S. M. Ohr. (1985) An electron microscope study of crack tip deformation and its impact on the dislocation theory of fracture. Mater. Sci. Engng 72, 1-35.

12. C. Pinna (1997) Etude de la propagation des fissures de fatigue sous chargement de cisaillement plan. Application à l'acier maraging M250. PhD Thesis, Ecole Polytechnique, Palaiseau, France.

13. D. F. Socie (1987) Fatigue damage maps. In: Proc. 3rd Int. Conf. on Fatigue and Fatigue Threshold (Edited by Ritchie and Starke), University of Virginia. EMAS, Wareley.

14. J. Lankford (1980) On the small crack fracture mechanics problem. Int. J. Fract. 16(1), R7-R9.

15. R. A. Smith (1983) Short fatigue cracks. In: Fatigue Mechanisms: Advances in Quantitative Measurement 
of Physical Damage (Edited by J. Lankford, D. L. Davidson, W. L. Morris and R. P. Wei), ASTM STP 811, 264-279.

16. C. Pinna and V. Doquet (1997) Quantification of friction effects during mode II fatigue crack propagation in a maraging steel. In: Proc. 5th Int. Conf. on Biaxial/Multiaxial Fatigue \& Fracture (Edited by E. Macha and Z. Mroz), Cracow, 8-12 September 1997, Vol. 2, 97-113.

17. S. Lynch and D. A. Ryder (1972) The fatigue behaviour of two aluminium-zinc-magnesium alloys. Scripta Met. 6, 181-186.

18. J. R. Rice (1992) Dislocation nucleation from a crack tip: an analysis based on the Peierls concept. J. Mech. Phys. Solids 40, 239-271.

19. Y. Sun, G. E. Beltz and J. R. Rice (1993) Estimates from atomic models of tension-shear coupling in dislocation nucleation from a crack tip. Mater. Sci. Engng A170, 67-85.

20. U. Essmann and K. Differt (1988) The nature of the wall structure in persistent slip bands of fatigued metals. Scripta Metall. 22, 1337-1342.

21. J. Lepinoux and L. P. Kubin (1985) In situ TEM observations of the cyclic dislocations behaviour in persistent slip bands of copper single crystals. Phil. Mag. A 51(5), 675-696.

22. B. A. Bilby, A. H. Cottrell, K. H. Swinden (1963) The spread of plastic yield from a notch. Proc. R. Soc. Lond. A, 272, 304-314.

23. J. Weertman, I. H. Lin and R. Thomson (1983) Double slip plane crack model. Acta Metall 31(4), 473-482. 